\title{
Automatic Data Reduction and Quantification of X-Ray Computed Tomography Images of Sedimentary Cores: Method and Illustration
}

\author{
Philippe Gaillot ${ }^{1,2}$, Mathieu J. Duchesne ${ }^{3}$, Peter Blum ${ }^{4}$ \\ ${ }^{1}$ ExxonMobil Exploration Company, Business Development, Spring, Texas, USA \\ ${ }^{2}$ Formerly at Center for Deep Earth Exploration-CDEX, Yokohama, Japan \\ ${ }^{3}$ Geological Survey of Canada-Québec Division, INRS Centre Eau, Terre et Environnement, Quebec, Canada \\ ${ }^{4}$ Integrated Ocean Drilling Program, College Station, Texas, USA \\ Email: *philippe.gaillot@exxonmobil.com
}

How to cite this paper: Gaillot, P., Duchesne, M.J. and Blum, P. (2020) Automatic Data Reduction and Quantification of X-Ray Computed Tomography Images of Sedimentary Cores: Method and Illustration. Open Journal of Geology, 10, 874-899. https://doi.org/10.4236/ojg.2020.108040

Received: July 2, 2020

Accepted: August 15, 2020

Published: August 18, 2020

Copyright $\odot 2020$ by author(s) and Scientific Research Publishing Inc. This work is licensed under the Creative Commons Attribution International License (CC BY 4.0).

http://creativecommons.org/licenses/by/4.0/

\begin{abstract}
This paper presents a procedure from which information contained in 3-Dimensional single energy X-ray computed tomography (XR-CT) images of sedimentary rocks is converted into sub-mm scale resolution core scalar and core image logs. This new data provide a quantitative and compact (data volume reduction of $90 \%$ ) description of the XR-CT images. Density-related outputs are calibrated through automatic integration with continuous digital visual core description (VCD) and discrete moisture and density (MAD) property index measurements of selected samples. After lithology-based calibration of the X-ray attenuation coefficients into density values, quantitative displays include: 1) histogram of the distribution of density values and its related statistical parameters, 2) radial and angular distributions of core density values, 3) volume, average density and mass contributions of three core fractions defined by density thresholds corresponding to voids or vugs (VV, density $\leq \sim 1 \mathrm{~g} \cdot \mathrm{cm}^{-3}$ ), and a break in the histogram of distribution of the density values showing the limit between the damaged (DM) and non-damaged (ND) fractions of the core material, and so, 4) providing a sub-mm scale bulk density core log free of any drilling disturbance. The procedure is illustrated on data from the $365 \mathrm{~m}$ deep Hole C9001C drilled off-shore Shimokita (northeast coast of Honshu, Japan). Usage of the outputs include: 1) derivation of sub-mm scale porosity core $\log , 2$ ) correction of volume sensitive measurements in case of poor core quality and partially filled core liner, and 3) seismic modeling and well ties.
\end{abstract}

\section{Keywords}

Core image, Multi-Sensor Core Logger, Ocean Drilling, Shimokita (Japan), 
Diatomaceous Silty Clays, Upper Miocene to Holocene

\section{Introduction}

Computer Tomography (CT) is a nondestructive, radiation recording technique, which maps the numerical values of the linear attenuation coefficient of $\mathrm{X}$ - or gamma- (photon) ray through a section of the investigated object. It requires the acquisition of two-dimensional radiographs for different positions during step-wise rotation around a central axis, whereby either the source and detector or the sample is moved. This is followed by the reconstruction of two-dimensional cross-sections perpendicular to the axis of rotation [1] [2]. First developed for applications in medicine [3], CT technology has been applied to various domains of geosciences [4] [5]. For more recent references, [6] reviews recent advances in computed tomography of geomaterials.

For work conducted on sedimentary rocks, CT investigation has both a qualitative and a quantitative approach. Qualitative investigations reveal various details of the core structure as bioturbation [7], heterogeneous discontinuities [8], alternate beddings in sandstones or partially filled fractures, vein selvage and vuggy porosity in limestone [9], biogenetic structures [10], invasion of the mud induced by the capillarity of the small scale porosity [11], facies succession composed of fine and thick rhythmites [12], and rotational fractures in air dried oil shales [13]. By assembling together more tomographic cross-sections, it is possible to obtain genuine 3-Dimensional (3D) representations of the investigated structures [14]. Because sedimentary structures reflect the environmental conditions during their accumulation, CT has been also used in description of facies as a result of transport and climatic processes [12] [15]. The quantitative approach in single energy CT scanner is related to the determination of the sediment bulk density. Recent quantitative use of dual energy CT scanner is not discussed in this paper. Based on core-to-core calibration, single energy CT has been used with good results to determine both vertical and transverse profiles of the bulk density of marine cores [12] [16]. The same technique has shown, for the oil shales of Cassuarina Basin (Australia), the presence of a strong positive correlation between attenuation coefficients and bulk density of air dried shales together with a moderately strong inverse correlation between the attenuation coefficients and modified Fisher assay oil yield [13]. The same kind of linear calibration curves have been experimentally confirmed for a number of synthesized cores composed by sand, silt and clay, saturated either with marine or fresh water [17]. Reference [18] quantitatively evaluated the attenuation contrast of various minerals using a medical X-ray CT scanner. More recently, [19] investigated the relationship between longitudinal (topograms) and transversal (tomograms) intensity scales to extract bulk density from its. Results showed excellent correlations between converted topogram values and Hounsfield Unit (HU) values obtained on the tomograms, as well as between relative bulk densities de- 
rived from the converted topogram values, and the absolute bulk density of various minerals.

In the framework of the Integrated Ocean Drilling Program

(http://www.iodp.org/), non-invasive XR-CT scanning of cores is now routinely available on-board the Japanese drilling vessel, Chikyu, operated by the Japan Agency for Marine-Earth Science and Technology (JAMSTEC). As CT generates large data volumes, it requires considerable computer resources for visualization, analysis and archiving. As an example, medical-type X-ray Computed Tomography (XR-CT) imaging of a $1 \mathrm{~m}$-long core provides 1600 core transverse slices (i.e. one $512 \times 512$ pixel image every $0.625 \mathrm{~mm}$ ) for a total data volume of about 200 Megabytes. A standard two months IODP expedition usually recovers at least $2 \mathrm{~km}$ of core resulting in 0.4 Terabytes of data and more than 3 million slices. The objective of this paper is to present a procedure for automatic data reduction (by about 90\%) and automatic quantification of CT images facilitating integration of such 3D data set with standard on-board data and post-cruise results. The proposed method uses medical type CT images of cores to automatically 1 ) identify voids/vugs; 2 ) identify the damaged core fractions of the core and convert it into a semi-quantitative core quality indicator; 3 ) identify local variations of core linear attenuation coefficient in terms of radial and angular distributions; and once properly calibrated with lithology-based discrete moisture and density (MAD) property index measurements 4) derive a sub mm-resolution bulk density core log to further compare with routine multi-sensor core logger (MSCL) continuous gamma ray attenuation (GRA) density core log. The procedure is described step-by-step and illustrated with diatomaceous silty clays core data collected in 2007 at Hole C9001C (offshore Shimokita, northeast coast of Honshu, Japan) [20]. Result of NantroSEIZE Stage 1 (IODP Expeditions 314, 315 and 316) are available on-line at http://www.pgaillot.com/Work.

Available core materials and on-board main core analysis techniques are presented. The principles, assumptions, acquisition and systematic errors of the MAD methodology are first introduced as of prime importance during calibration of the XR-CT derived density. Next, the principles and acquisition settings of GRA and XR-CT data collected on-board are presented. Detailed steps of the procedure for reduction of stored data volume and quantification of XR-CT images are described. MAD-density, GRA-density and XR-CT derived density are compared and discussed in term of data quality. Finally, usages of the outputs of the data reduction of the $3 \mathrm{D}$ XR-CT images for 1) derivation of sub-mm scale porosity core $\log , 2$ ) correction of volume sensitive measurements in case of poor core quality and partially filled core liner, and 3) seismic modeling (synthetic seismogram) and well ties, are presented.

\section{Materials \& Methods}

\subsection{Materials}

The procedure for automatic data reduction of core CT images and production 
of sub mm-resolution XR-CT derived bulk density core $\log \left(\rho^{\mathrm{XRCT}}\right)$ is illustrated using data from $386 \mathrm{~m}$ of core samples collected from a $365 \mathrm{~m}$ deep hole (C9001C) drilled offshore Shimokita (Japan, $41^{\circ} 10.6380^{\prime} \mathrm{N}, 14^{\circ} 12.081^{\prime} \mathrm{E}$; water depth $1180 \mathrm{~m}$ ) during the shakedown cruise (CK06-06) of the drilling vessel Chikyu. The averaged core expansion upon recovery was $\sim 7 \%$ with peak values of $10 \%-15 \%$ per $10-\mathrm{m}$ long core. The core is composed of four units of unconsolidated sediments of Upper Miocene to Holocene age dominated by finegrained material [20].

Following a standard on-board core processing workflow, the recovered cores (core barrel $\sim 9.5 \mathrm{~m}$ long) were cut into $\sim 1.5 \mathrm{~m}$ long sections and scanned with a medical-type XR-CT scanner (GE Medical System Light Speed Ultra16; [21]). The X-ray tube voltage and current were set to $120 \mathrm{kV}$ and $100 \mathrm{~mA}$, respectively. Measurement interval of the helical scan has been set to $0.625 \mathrm{~mm}$ under the 16 arrays of detectors mode. In this scan mode, three minutes are required to scan a $1.5 \mathrm{~m}$ section, five minutes for mathematical reconstruction using Image Works software (http://www.imageworkscorporation.com/productdrivers), and five additional minutes for data format conversion and transfer.

After XR-CT scanning, selected whole core segment (typically $10-30 \mathrm{~cm}$ long) were taken for further investigation of ephemeral properties (interstitial water and microbiology analyses). The remaining whole core sections were scanned using multi-sensor core logger at $4-\mathrm{cm}$ measurement intervals for gamma ray attenuation (GRA) density, magnetic susceptibility (MS), natural gamma radiation (NGR), resistivity (RES) and P-wave (PWV) velocity. The core sections were subsequently split, visually described in term of lithology and sedimentary features (visual core description, VCD), and finally sampled for other physical and chemical analyses [20]. For the purpose of this study, and especially validation of the XR-CT derived bulk density $\left(\rho^{\mathrm{XRCT}}\right)$, the most relevant among all these discrete analyses are MAD property index measurements resulting in high-quality (i.e. drilling disturbance free) core bulk density ( $\left.\rho_{\text {Bulk }}^{\text {MAD }}\right)$, grain density $\left(\rho_{\mathrm{SOLID}}^{\mathrm{MAD}}\right)$ and porosity $\left(\phi^{\mathrm{MAD}}\right)$ data. Before presenting the results of data reduction of XR-CT images and their applications, the principles, acquisition, and processing of the MAD, GRA and XR-CT scan data to the two-phase (minerals and interstitial water) system model for sediments and rocks are first summarized

\subsection{Moisture and Density of Discrete Sample}

In a technique known as MAD, moisture (porosity) and density of discrete samples can be estimated from mass and volume measurements of the sample before and after removal of interstitial pore fluid through drying via a convection oven. The principle of this technique relies on phase-relation equations (extracted water by drying is assumed to be interstitial pore fluid) and correction for the mass and volume of salt precipitated during the drying process [22].

Practically, MAD measurements of the current data set were routinely meas- 
ured using $\sim 10 \mathrm{~cm}^{3}$ samples from split cores collected at a frequency of two per core (i.e., every $5 \mathrm{~m}$ ), taking care to sample undisturbed parts of the core and avoid drilling slurry and "biscuits" (broken pieces of cores). Sampling frequency was increased as needed to characterize all significant changes of lithology. Immediately after samples were collected, wet sediment mass was measured. Samples were then placed in a convection oven for 24 hours at a temperature of $105^{\circ} \mathrm{C} \pm 5^{\circ} \mathrm{C}$. After drying, dry sediment mass and dry sediment volume were measured. Sample mass was determined on board to a precision of $\pm 0.01 \mathrm{~g}$ using an electric motion compensated balance system (error less than $1 \%$ with 0.1 $\mathrm{g}$ of sample). Volumes were determined using a helium five-chambered pycnometer with an approximate precision of $\pm 0.02 \mathrm{~cm}^{3}$.

\subsection{Gamma Ray Attenuation Density}

Bulk density of sediments and rocks can also be estimated from the measurement of gamma ray attenuation (GRA) of medium-energy gamma rays (100 $1000 \mathrm{keV}$ ) [23]. The continuous measurement of whole core section density relies on a ${ }^{137} \mathrm{Cs}$ source (used transmits gamma rays at $660 \mathrm{keV}$ ) and a standard $\mathrm{NaI}$ scintillation detector coupled with a photo-multiplier. In the on-board equipment setting, the collimator used is $5 \mathrm{~mm}$ in diameter and the spatial resolution of the sensor is about $0.5 \mathrm{~cm}$. Measurements with the present system have typically count rates of $20,000 \mathrm{cps}$ (soft mud). If measured for $4 \mathrm{~s}$, as in the current core flow, the statistical error is therefore less than $40,000 \pm 200$, or $0.5 \%$. However, accuracy is limited by the assumption that the measured material has the same attenuation coefficient as the calibration standards used. For general sediment water mixtures, this should be the case and errors should be less than $5 \%$.

\subsection{X-Ray Computed Tomography Images}

The operating energy range of the present-day XR-CT scanners is between 30 and $200 \mathrm{keV}$, and the linear attenuation coefficient $\mu$ is a function of both bulk density and effective atomic number of the sample.

Image quality optimization requires a reduction of artifacts, which are inherent to the XR-CT technique. Several common types of artifacts can already be reduced to some extent by optimizing acquisition conditions, but a further reduction during reconstruction is often needed [24]. The most important artifacts in XR-CT images are related to "beam hardening", which refers to the preferential attenuation of low-energy X-rays when a polychromatic X-ray beam, typical of medical XR-CT scanners equipped with X-ray tubes, passes through an object. For beam-hardening artifact reduction during reconstruction, linearization procedures are highly recommended for monomineralic systems [24]. For polymineralic systems, a dual energy approach allows a dramatic improvement in image quality [25].

For inhomogeneous samples, the attenuation coefficient has different values 
for different points of the investigated object. At the end of the reconstruction process, the values of the attenuation coefficient $\mu_{(x, y)}$ corresponding to each voxel results are expressed in Hounsfield Units (HU), following the relation shown in Equation (1)

$$
\mathrm{HU}_{(x, y)}=\left(\mu_{(x, y)}-\mu_{w}\right) /\left(\mu_{w}-\mu_{a}\right) \times 1000
$$

where $\mu_{w}$ and $\mu_{a}$ are the linear attenuation coefficients of the water and air, respectively.

\section{Data Reduction of XR-CT Images}

The result of the mathematical reconstruction and reformatting of the $3 \mathrm{D}$ XR-CT images is a set of transversal core slices (tomograms) with a separating distance of $0.625 \mathrm{~mm}$ between slices and a pixel size of $0.1875 \mathrm{~mm} \times 0.1875 \mathrm{~mm}$ within the slice. A total of $\sim 580,000$ slices were recorded for this core dataset, and, thus the need for development of a procedure for automatic data reduction. As the 3D images of cores is a set of co-axial (aligned) core transversal 2D slices, the procedure for automatic data reduction of XR-CT images of cores is automatically and sequentially applied to each individual slice. For each slice, the algorithm essentially automates what a skilled analyst does when interpreting a XR-CT image. The algorithm consist of six steps and is illustrates in Figures $1-6$.

\subsection{Core Extraction (Step 1)}

XR-CT slices are 512 pixels $\times 512$ pixels in size DICOM (Digital Imaging and Communication in Medicine) format images in HU. The first step of the procedure is to extract the core image by detecting the plastic core liner and so, isolate the core material representing the only portion of the image of geological interest (i.e. the core itself). At the resolution of the image, the position, diameter, thickness and shape of the core liner can vary from slice to slice. However, the core liner can be detected by the contrast in attenuation coefficient of air (negative HU) and plastic (positive HU; see Table 1). This a-priori simple step is sometimes complicated by localized mathematical artifacts and/or partial volume effects inherent to CT reconstruction. Example of artifacts and impact on core liner detection are illustrated in Figure 1. For the Shimokita core samples, automatic core liner detection failed for $\sim 2.8 \%$ of the slices $(16,186 / 582,916)$, most of them being located at the top or the bottom of the cores sections (i.e. core end-caps and empty section intervals), thus having a limited impact on the following use of the results.

\subsection{Calibration of X-Ray Attenuation Coefficient into Bulk Density (Step 2)}

An empirical relationship between XR-CT attenuation coefficient and bulk density, $\rho$, can be established by scanning materials of known bulk density. To avoid 
Table 1. Bulk density ( $\rho$ ) - XR-CT attenuation coefficient (HU) used for calibration of the medical type XR-CT scanner used in this work. $\sigma$. standard deviation on HU value.

\begin{tabular}{cccc}
\hline \multirow{2}{*}{$\begin{array}{c}\text { Calibration } \\
\text { Material }\end{array}$} & $\begin{array}{c}\text { Bulk density } \\
\rho\left(\mathrm{g} \cdot \mathrm{cm}^{-3}\right)\end{array}$ & X-ray CT Attenuation Coefficient \\
\cline { 3 - 4 } Air & 0.00 & -1000 & $\sigma(-)$ \\
\hline Pure water & 1.00 & 0 & - \\
Plastic & 1.10 & 115 & - \\
Glass & 2.15 & 1492 & 12 \\
Aluminum & 2.70 & 2810 & 22 \\
\hline
\end{tabular}

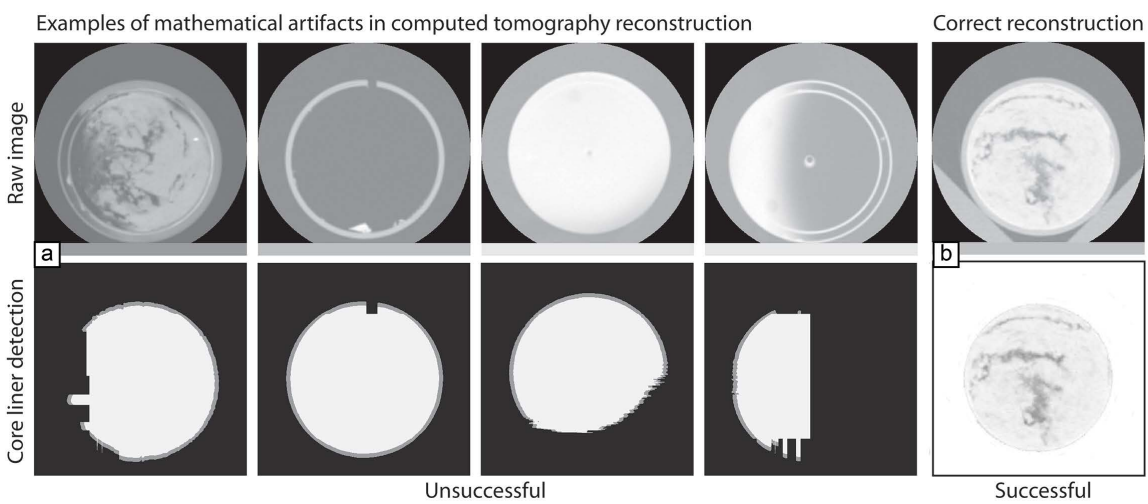

Figure 1. (a) Examples of mathematical artifacts in reconstruction of X-ray computed tomography (XR-CT) image (top) resulting in unsuccessful core liner detection (bottom) where the background is automatically set to black, the core-liner is set to gray and the internal core liner fraction is set to white. Note that in this set of images, the core liners are not initially displayed as a continuous thick gray zone as it could be expected in correctly reconstructed images where the core liner detection is successful (b).

any complications related to XR-CT scanner geometry, mathematical reconstruction algorithm and physical photoelectric and Compton effects, a normal practice is to use pellets of controlled bulk density made of the same rock material as the core analyzed [26]. In the current workflow, discrete MAD samples combined with digital VCD have been used as lithology-controlled natural pellets. The range of calibration has been expended by using air, water, glass and aluminum standards. The resulting empirical relationship (Equation (2)) relating $\rho_{\mathrm{BULK}}^{\mathrm{MAD}}$ to XR-CT HU values is slightly non-linear (second order polynom, $\mathrm{R}^{2} \sim 0.75$; Figure 2).

$$
\rho^{\mathrm{XRCT}}=-10^{-7} \mathrm{HU}^{2}+9 \times 10^{-4} \mathrm{HU}+1
$$

Note that in spite of its slightly non-linear form, this relationship is in agreement with the calibration data of the XR-CT scanner and the definition of the $\mathrm{HU}$ where a $\mathrm{HU}$ of 0 well corresponds to a density of $1.0 \mathrm{~g} \cdot \mathrm{cm}^{-3}$ (pure water), and where a $\mathrm{HU}$ of -1000 corresponds to the expected density of $0.0 \mathrm{~g} \cdot \mathrm{cm}^{-3}$ (air). This latter relationship is thought to be appropriate for the current XR-CT scanner configuration and settings, and the lithology encountered at this site. 


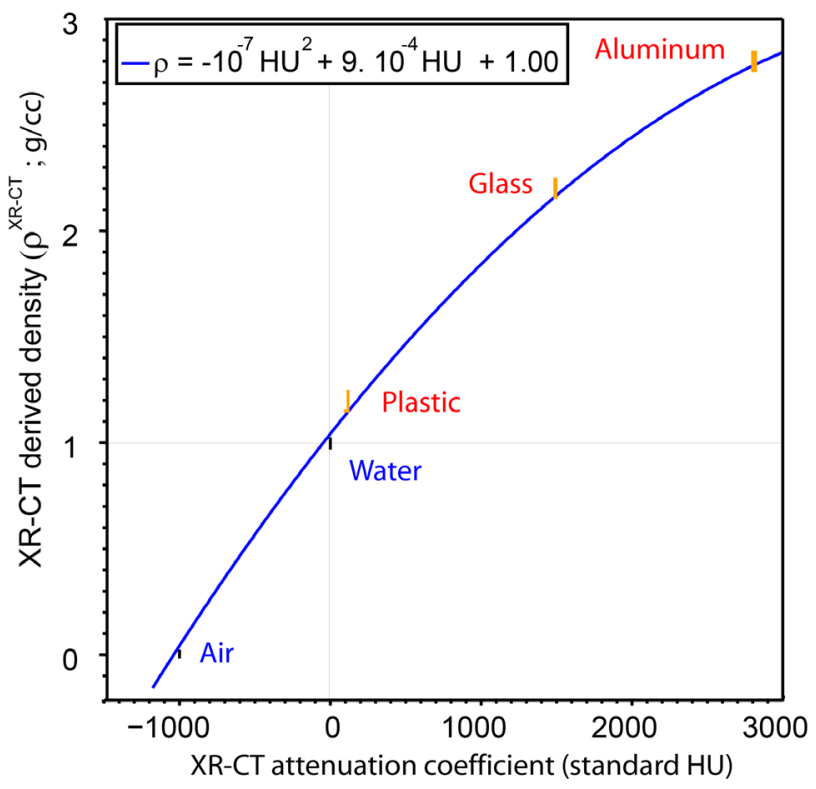

Figure 2. Empirical relationship between X-ray Computed Tomography (XR-CT) attenuation coefficients (standard Hounsfield unit, HU) and XR-CT derived density values $\left(\rho^{\mathrm{XRCT}}\right)$. Also shown calibration pieces (plastic, glass and aluminum) initially used to check the calibration of the XR-CT scanner outside of the $\left[0-1 \mathrm{~g} \cdot \mathrm{cm}^{-3}\right]$ range defined by air and pure water (see Table 1). The size of the symbols is proportional to the standard deviation of the $\mathrm{HU}$ and density values of the calibration pieces.

\subsection{Distribution of Bulk Density Values (Step 3)}

Once the XR-CT attenuation coefficients of each core slice are converted into density values (Figure 3(a)), the histogram of distribution of the density values is computed (Figure $3(\mathrm{~b})$ ). Standard statistical parameters, such as mean, median, and various percentiles $(10 \%, 25 \%, 75 \%$ and $90 \%)$ are automatically extracted. While the histogram can be displayed with depth as an image (array) of the core $\log$ (Figure 5(b)), the statistical parameters can be displayed more easily as scalar logs (Figure 5(c)). The distance between the median and the mean $\left(\left|\rho_{50 \%}^{\mathrm{XRCT}}-\rho_{\mathrm{TOTAL}}^{\mathrm{XRCT}}\right|\right)$ as well as the width at half height (WHH) of the histogram, provide two quantitative measures of the dispersion of the density values (Figure 3(b); Figure 5(d)). These indicators are color-coded to further assist the analysis of the distribution of the density values. Rules to define color coding are user-defined, but a good practice relies on statistical analyses of the distribution of these dispersion indicators. For the core data used in this work, four classes have been defined from the histograms of distribution of the dispersion measures. Resulting rules are given in Table 2.

\subsection{Thresholding and Phase Identification (Step 4)}

From the histogram of distribution of density values, one can define two thresholds (Figure 3(b)). The first threshold (Tvv) corresponding to the standard pore water density $\left(\rho_{\mathrm{pw}}^{\text {STANDARD }}=1.025 \mathrm{~g} \cdot \mathrm{cm}^{-3}\right)$ marks the upper limit for voids/vugs (VV). Based on the shape of the histogram, a second threshold $\left(\mathrm{T}_{\mathrm{DM}}\right)$ 
Table 2. Rules and color-coding of automatic measures of the dispersion of $\rho_{\text {TOTAL }}^{\text {XRCT }}$ values based on the distance between $\rho_{50 \%}^{\text {XRCT }}$ and $\rho_{\text {TOTAL }}^{\text {XRCT }}$ (top) and the width at half height (WHH) of the histogram of distribution of $\rho_{\text {TOTAL }}^{\text {XRCT }}$ values (bottom).

\begin{tabular}{ccccc}
\hline Class & Min. & Max. & Description & Color \\
\hline & \multicolumn{2}{c}{ Dispersion measure based on } & $\rho_{50 \%}^{\text {XRCT }}-\rho_{\text {TOTAL }}^{\text {XRCT }} \mid$ & \\
1 & 0.000 & 0.025 & Low & Green \\
2 & 0.025 & 0.075 & Moderate & Yellow \\
3 & 0.075 & 0.150 & High & Orange \\
4 & 0.150 & 5.000 & Very-high & Red \\
& Dispersion measure based on width at half height $($ WHH $)$ of $\rho^{\text {XRCT }}$ histogram \\
1 & 0.00 & 0.10 & Low & Green \\
2 & 0.10 & 0.15 & Moderate & Yellow \\
3 & 0.15 & 0.20 & High & Orange \\
4 & 0.2 & 5.00 & Very-high & Red \\
\hline
\end{tabular}

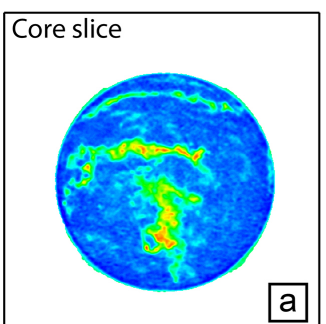

Total volume $\left(\mathrm{cm}^{3}\right): 4.38$ $\rho_{\text {TOTAL }}^{\text {XR-CT }}(\mathrm{g} / \mathrm{cc}): 1.31$

Total mass $(\mathrm{g}): 5.7420$

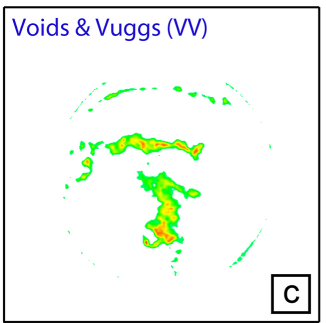

Volume fraction (\%) : 10.54

$\rho_{\mathrm{vV}}^{\mathrm{XR}-\mathrm{CT}}(\mathrm{g} / \mathrm{cc}): 0.70$

Mass fraction (\%) : 5.62

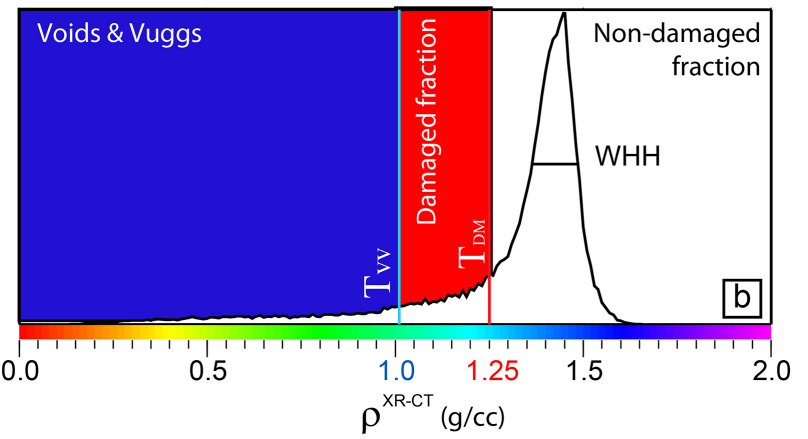

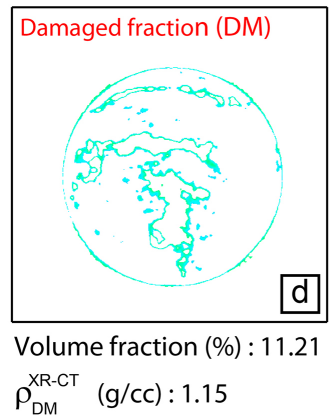

Mass fraction (\%) : 9.81

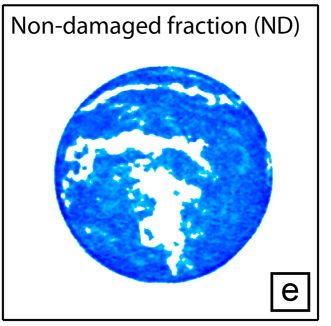

Volume fraction (\%) : 78.25

$\rho_{\mathrm{ND}}^{\mathrm{XR}-\mathrm{CT}}(\mathrm{g} / \mathrm{CC}): 1.42$

Mass fraction (\%) : 84.57

Figure 3. Automatic characterization of X-ray computed tomography (XR-CT) slice in terms of volume distribution, average density, and mass contribution of the voids/vugs (VV), damaged (DM) and non-damaged (ND) core fractions. (a) XR-CT slice converted into density values using empirical relationship shown in Figure 2; (b) Histogram of distribution of density values $\left(\rho^{\mathrm{XRCT}}\right)$ from which two threshold values $\left(\mathrm{T}_{\mathrm{VV}}\right.$ and $\left.\mathrm{T}_{\mathrm{DM}}\right)$ and the width at half height (WHH) of the histogram are defined; ((c), (d), and (e)) Results of thresholding for the voids and vugs (VV), damaged (DM) and non-damaged (ND) core fractions, respectively. Slice 302056 from core section C9001C-18H2, 160.9916 m curated core depth below seafloor. 
marks the upper limit of the damaged core material fraction (DM), and the remaining fraction being the non-damaged (ND) core material fraction. Applying these thresholds to the density version of the XR-CT slice, the volume, the average density and mass contributions of each individual fraction (VV, DM, ND) of the core material can be individually estimated (Figure 3(c) to Figure 3(e)).

Two XR-CT-derived bulk density measurements are of primary importance while comparing those density estimates with available MAD- and GRA-density data for this core dataset: 1 ) the first measurement is the average bulk density of the slice, $\rho_{\mathrm{TOTAL}}^{\mathrm{XRCT}}$, that equally integrates the $\mathrm{VV}, \mathrm{DM}$ and $\mathrm{ND}$ fractions of the core material, 2) the second measurement is the average density of the isolated $\mathrm{ND}$ fraction of the core, bulk density of the slice, $\rho_{\mathrm{ND}}^{\mathrm{XRCT}}$, thought to be free of any drilling disturbance as voids/vugs and core damaged effects are not included in this measurement. In the example of Figure 3, where the VV and DM fractions respectively equal $10.54 \%$ and $11.21 \%$ of the slice volume, $\rho_{\text {TOTAL }}^{\mathrm{XRCT}}$ equals $1.31 \mathrm{~g} \cdot \mathrm{cm}^{-3}$ while $\rho_{\mathrm{ND}}^{\mathrm{XRCT}}=1.42 \mathrm{~g} \cdot \mathrm{cm}^{-3}$, a $7.8 \%$ difference in bulk density value.

Percentage of VV and DM core fraction can further be used to automatically provide a semi-quantitative core quality estimator color-coded according to user define rules. The rules used in this work are given in Table 3 and resulting distribution of core quality estimates is given in Figure 5(f) and Figure 6.

\subsection{Angular and Radial Distribution (Step 5)}

After having computed the center of the core, the angular and radial distributions of the original XR-CT attenuation coefficients and/or bulk density values after calibration (see Step 2) are computed. The angular XR-CT attenuation coefficients (resp. density values) distribution is computed by averaging the XR-CT coefficients (resp. density values) contained in different rotating angular sectors of the core (Figure 4(a)). The radial distribution of XR-CT attenuation coefficients (resp. density values) is computed by averaging the coefficient (resp. density values) contained in running averaged annuli of constant thickness and increasing diameter (Figure 4(b)). The size of the angular sector and the thickness of the annulus used in moving average computations are user-defined parameters of the analysis. For the current work, angular sector is set to 10 degrees and annulus thickness is set to $1.5 \mathrm{~mm}$ (8 pixels), as a good compromise between computation time and resolution of the outputs.

Table 3. Rules for color-coding of automatic core quality indicator based on volume of voids/vugs (VV) and damaged (DM) core fractions.

\begin{tabular}{cccc}
\hline Class & Rule. & Description & Color \\
\hline 0 & & No Data & White \\
1 & $\mathrm{VV} \geq 30 \%$ & Bad & Red \\
2 & $\mathrm{DW} \geq 10 \%$ & Damaged & Yellow \\
3 & Otherwise & Good & Green \\
\hline
\end{tabular}



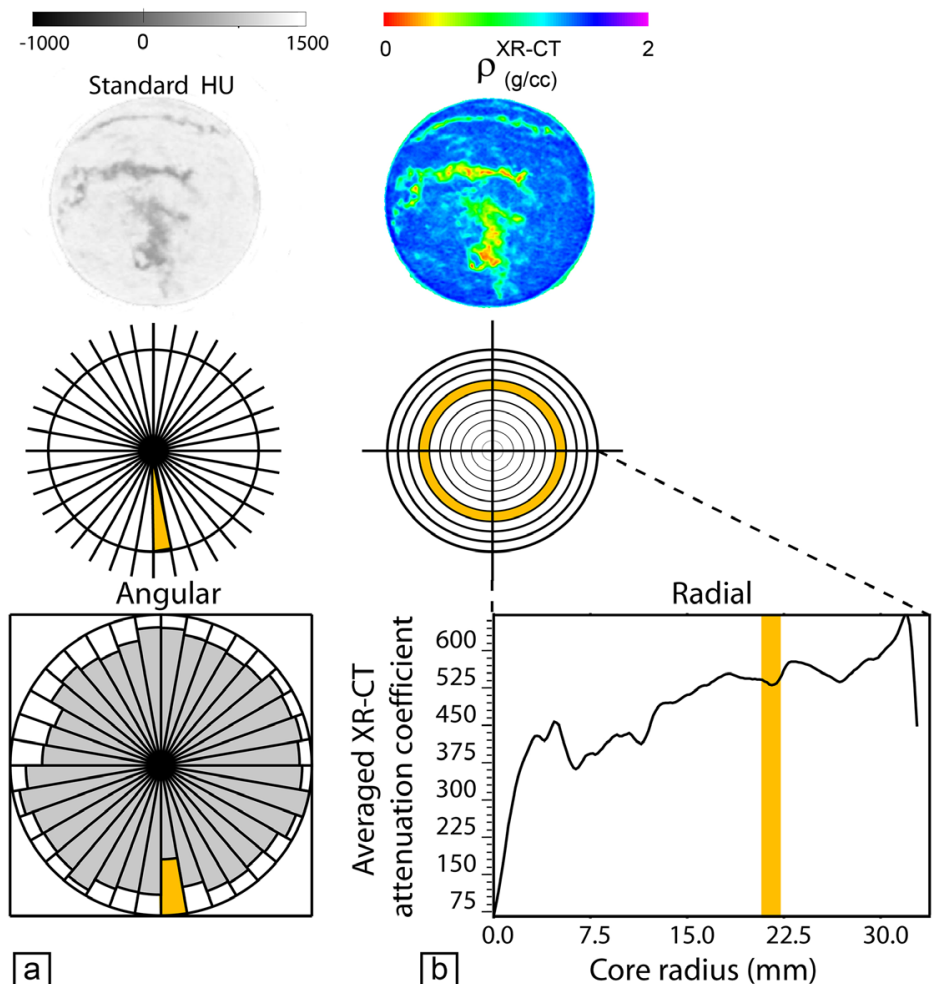

a

$\mathrm{b}$

Figure 4. Principle of computation of a) the angular and b) the radial distributions of the $\mathrm{X}$-ray computed tomography (XR-CT) attenuation coefficients (HU, left) or density values ( $\rho^{\mathrm{XRCT}}$, right). Slice 302056 from core section C9001C-18H2, $160.9916 \mathrm{~m}$ curated core depth below seafloor.

\subsection{Visualization-Plotting (Step 6)}

Combining all the quantitative information automatically extracted on all the slices, synthesis depth-plots are automatically produced using the Borehole Geology and Geophysics package [27] relying on the graphical capabilities of the Generic Mapping Tools [28]. An example of summary figure for the section C9001C-11H4 (96.82 - $98.32 \mathrm{~m}$, curated core depth below seafloor) is given in Figure 5.

Figure 5 includes (a) The raw XR-CT images (horizontal and vertical longitudinal core sections) after core liner detection and extraction of core material (step 1) showing 1) numerous relatively uniformly vertically spaced voids $(0.65$ to $0.1 \mathrm{~cm}$ thickness dark semi-horizontal features), associated to clay expansion/contraction during the core recovery process (quickly bringing material from in-situ pressure and temperature to surface condition), 2) two abrupt lithology changes (at 97.75 and $97.84 \mathrm{~m}$ ), one clast inclusion (97.96 - $97.99 \mathrm{~m}$ ), and finally a biscuited portion (core pieces) at the bottom of the core section (98.23 $98.3 \mathrm{~m})$;

(b) The histogram of bulk density values and (c) its statistical representation (mean, 10\%-, 25\%-, 50\%-, 75\%- and 90\%-tiles) displayed as core logs (steps 2 and 3) well mimic the above described rhythmic patterns of voids, lithology changes, and the biscuited core section; 


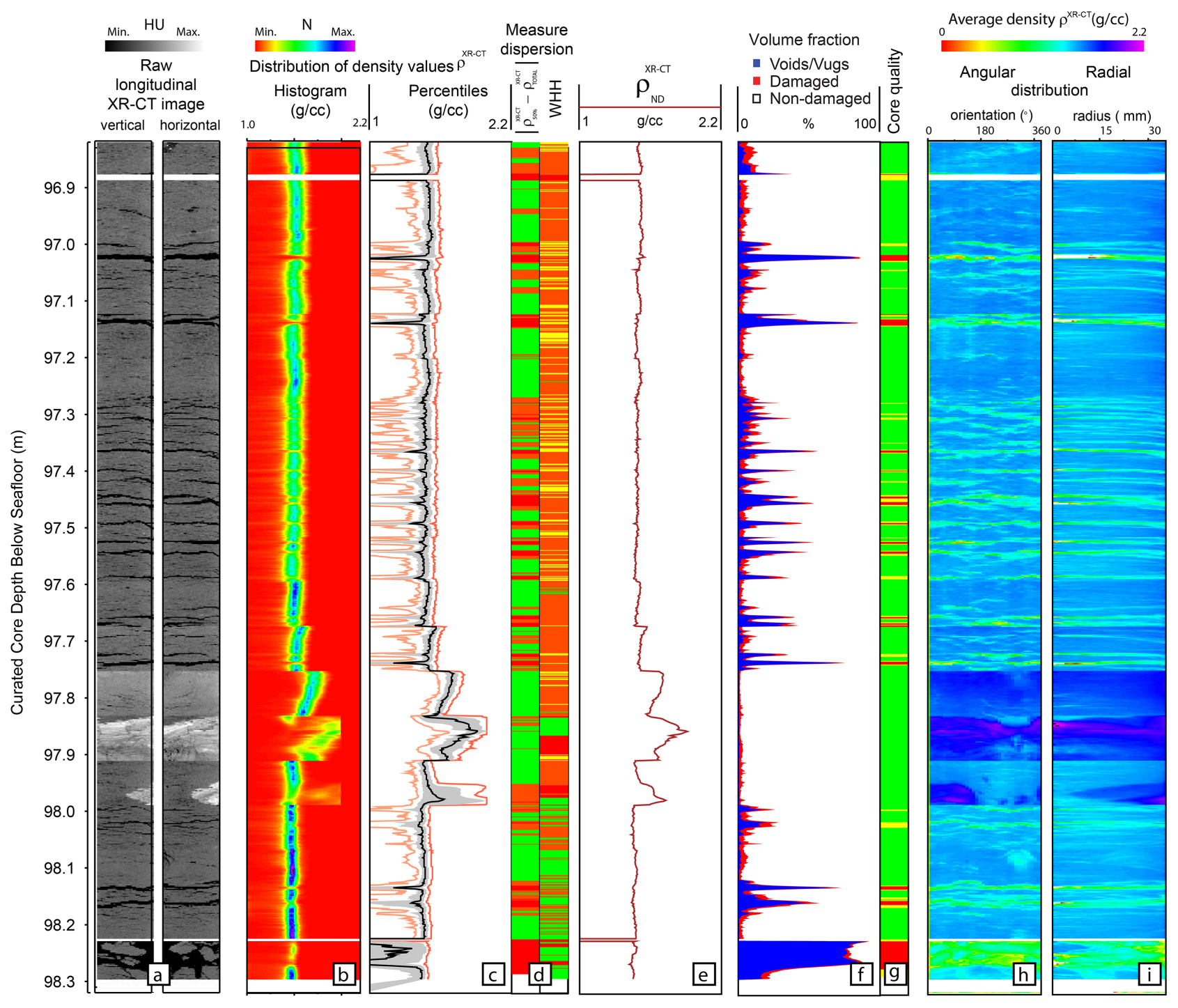

Figure 5. Synthesis plot of quantitative information automatically extracted from 3D X-ray computed tomography (XR-CT) images of the core section C9001C-11H4 (96.82 - $98.32 \mathrm{~m}$, curated core depth below seafloor). See text for detailed description.

(d) Two color-coded measures of dispersion of the density values based on the distance between XR-CT-derived mean density $\left(\rho_{\text {TOTAL }}^{\text {XRCT }}\right)$ and $50 \%$-tile density $\left(\rho_{50 \%}^{\mathrm{XRCT}}\right)$ and the width at half height maximum (WHH) of the histogram of distribution of density values (step 3; Table 2). Based on this example, $\left|\rho_{\text {TOTAL }}^{\mathrm{XRCT}}-\rho_{50 \%}^{\mathrm{XRCT}}\right|$ appears to be a better indicator of the degree of homogeneity of the core than WHH.

(e) Volume fraction of the voids/vugs (VV), damaged (DM) and non-damaged (ND) core fractions (step 4) clearly identifying voids related to clay expansion/contraction and core biscuit;

(f) Color-coded core-quality estimator automatically derived from the abundance of VV and DM fractions (step 4, Table 3); in particular, this core-quality indicator constitutes a reliable and automatic source of information for assessing the impact of drilling/coring disturbance and partly filled core liner on vo- 
lume-sensitive core logging data such as gamma ray attenuation density ( $\rho^{\mathrm{GRA}}$ ), magnetic susceptibility (MS) and natural gamma radiation (NGR).

(g) Very-high vertical resolution (mm-scale) XR-CT derived average density of the non-damaged core fraction ( $\rho_{\mathrm{ND}}^{\mathrm{XRC}}$; step 4 ), thought to be free of all drilling/coring disturbance and, thus, best to estimate core bulk density $\left(\rho_{\mathrm{BULK}}^{\mathrm{CORE}}\right)$;

(h), (i) Angular and radial distributions of the density values (step 5 after calibration of attenuation values into density, step 2); When all slices of a given core section are combined, the unwrapped image of the angular distribution is similar to borehole wall images or a 360-degrees digital scan of the core surface where beddings and structural features can be recognized as sine waves (Figure $5(\mathrm{~h})$ ). This output can further be integrated with geographically oriented borehole wall images, such as wireline electrical micro-imaging or logging while drilling density images, if available, to back orient the cores [29]. Indeed, when non-ambiguous common features are recognized on both sets of images, cores can be geographically oriented and so provide unique source of information for detailed structural and paleomagnetic studies. Because such data were not available for hole C9001C, this possible use of the outputs is not discussed in the Application section.

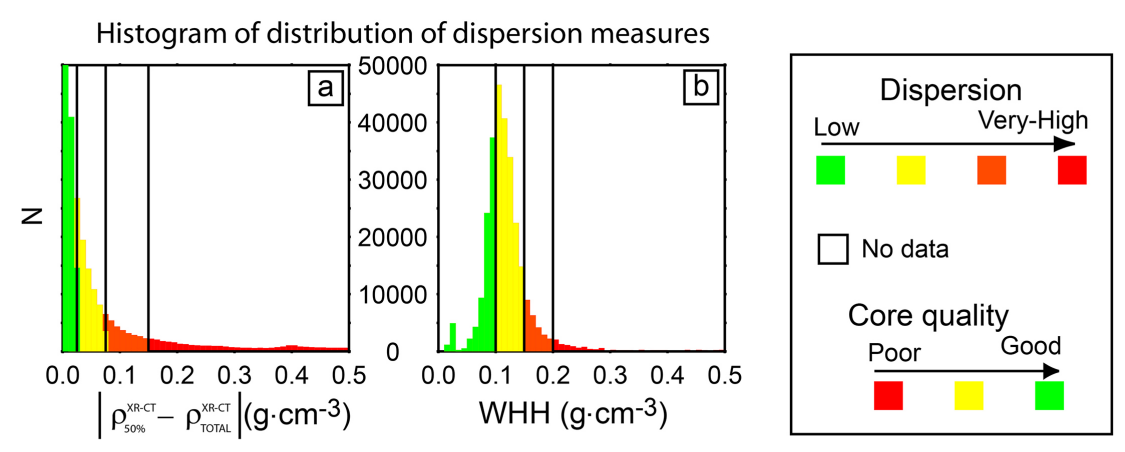

Histograms of dispersion and core quality distributions vs. $\rho_{\text {TOTAL }}^{\text {XR-CT }}(\mathrm{g} / \mathrm{CC})$
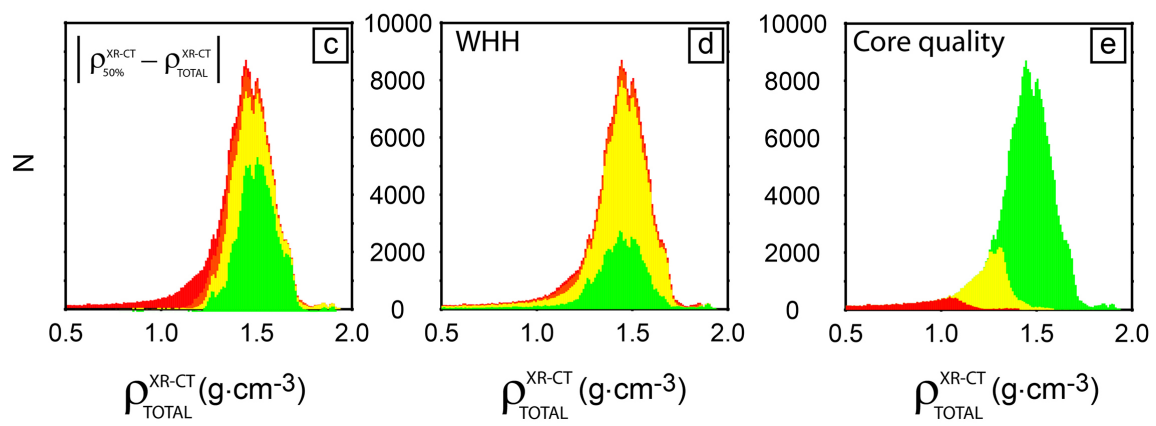

Figure 6. Distribution of dispersion of density values based on (a) the distance $\left|\rho_{50 \%}^{\mathrm{XRCT}}-\rho_{\mathrm{TOTAL}}^{\mathrm{XRCT}}\right|$ and (b) the width at half maximum (WHH) of the histogram of distribution of $\rho^{\mathrm{XRCT}}$ values (see text and Figure 3 for definition). Resulting histograms of distributions of automatic measures of dispersion of $\rho^{\mathrm{XRCT}}$ based on (c) $\left|\rho_{50 \%}^{\mathrm{XRCT}}-\rho_{\mathrm{TOTAL}}^{\mathrm{XRCT}}\right|$ and (d) WHH vs. $\rho_{\mathrm{TOTAL}}^{\mathrm{XRCT}}$. (e) Distribution of automatic core quality indicator vs. $\rho^{\mathrm{XRCT}}$ (histogram bin $\left.=0.025 \mathrm{~g} \cdot \mathrm{cm}^{-3}\right)$. 
The radial distribution plot (Figure 5(i)) provides information on radial variation that can help in diagnosing zones of bias in CT reconstruction (beam hardening characterized by radial attenuation), and/or zone of core expansion (low CT attenuation coefficient/low density in the center vs. high attenuation coefficient/density at the core periphery) or damage due to friction at the core liner interface (low CT attenuation coefficient/density at the core liner interface).

To take into account depth overlap between adjacent expanded cores (recovered core length $>$ drilled interval), drilling (bit depth, length of cored interval) and curatorial information (length of recovered core) are integrated to produce a new depth scale, known as scaled core depth below seafloor. In this scale depth, a curated core length longer than its corresponding drilled interval is linearly compressed to fit the drilled interval. In case the curated core length is shorter than the drilling interval (incomplete core recovery or no core expansion) the curated length is not modified and equals the scaled curated core depth (IODP depth scale terminology, IODP-MI internal report, not published). Providing that affine transforms between depth scales are available, both scalar and array (image) outputs can be displayed in any reference depth.

Array (image) logs, such as 1) the $2 \mathrm{D}$ vertical and horizontal longitudinal sections of the 3D XR-CT images, 2) the histogram of distribution of the density values, and 3) the angular and radial distributions of the density values usually carry too much resolution/details to be displayed at the borehole scale (assuming standard A4 or letter display size). Scalar logs, possibly filtered, and color-coded semi-quantitative indicators of core quality and density measure dispersion are more suitable for such overview plots.

\section{Applications}

By themselves quantitative and semi-quantitative outputs of the previously described procedure for data reduction and quantification of the XR-CT images are valuable parts of the full data integration framework. In particular the above described outputs and their 2D graphical representations provide a valuable screening tool to further guide core sampling and/or more detailed analysis of the 3D XR-CT images with specialized software. Based on the data available for Hole C9001C, this section quickly presents four examples of application of the outputs of the presented procedure. Examples include 1) validation of sub-mm scale XR-CT derived core bulk density, 2) derivation of sub-mm scale porosity, 3) correction of volume sensitive MSCL measurements (NGR, MS and possibly $\rho^{\mathrm{GRA}}$ ), and 4) core-seismic integration in the absence of well log (and acoustic data).

\subsection{Comparison of Bulk Density Results}

Figure 7 displays the entire $365 \mathrm{~m}$ of borehole C9001C in curated core depth below seafloor depth scale. In order to compare density values estimated from $\operatorname{MAD}\left(\rho_{\mathrm{BULK}}^{\mathrm{MAD}}\right), \mathrm{GRA}\left(\rho^{\mathrm{GRA}}\right)$ and XRCT $\left(\rho_{\mathrm{ND}}^{\mathrm{XRCT}}, \rho_{\mathrm{TOTAL}}^{\mathrm{XRCT}}\right)$, Figure 7 includes $(\mathrm{a})$ the core recovery column, (b) lithologic units, (c) volume of VV, DM and ND 
core fractions, (d) color-coded core quality indicator, (e) percentiles of the histogram of distribution of densities values, (f) color-coded estimates of bulk density measure dispersion, (g) the comparison of $\rho_{\mathrm{BULK}}^{\mathrm{MAD}}$ and $\rho_{\mathrm{ND}}^{\mathrm{XRCT}}$, (h) the comparison between $\rho^{\mathrm{GRA}}$ and $\rho_{\mathrm{TOTAL}}^{\mathrm{XRCT}}$, and finally (i) the MSCL natural gamma radiation (NGR) core log as proxy for lithological variations.

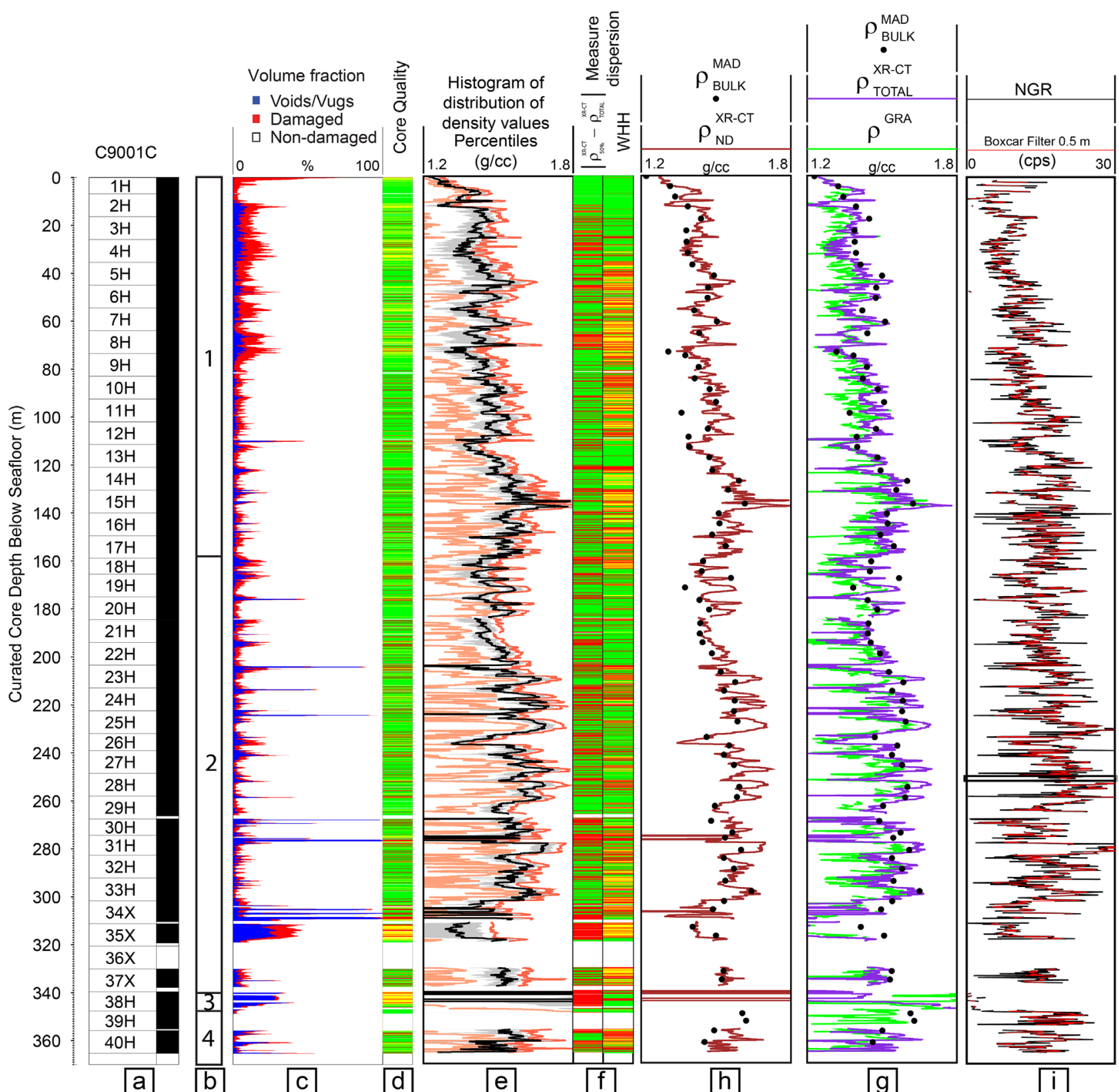

Figure 7. Comparison of available density estimates at Hole C9001C (curated core depth below seafloor). (a) Core recovery column; (b) Lithologic units, (c) Percentage of the volume of voids/vugs (VV), damaged (DM) and non-damaged (ND) core material fractions; (d) Color-coded core quality indicator; (e) Percentiles (10-left, 25-lower gray limit, 50-black, 75-upper gray limit, 90-right) of the distribution of XR-CT derived density values $\left(\rho^{\mathrm{XRCT}}\right)$; f) Color-coded dispersion measures of $\rho^{\mathrm{XRCT}}$ based on $\left|\rho_{50 \%}^{\mathrm{XRCT}}-\rho_{\mathrm{TOTAL}}^{\mathrm{XRCT}}\right|$ and WHH (see text for details); (g) Comparison between $\rho_{\mathrm{ND}}^{\mathrm{XRCT}}$ and $\rho_{\mathrm{BULK}}^{\mathrm{MAD}}$; (h) Comparison between $\rho_{\mathrm{TOTAL}}^{\mathrm{XRCT}}$ and $\rho^{\mathrm{GRA}}\left(\rho_{\mathrm{BULK}}^{\mathrm{MAD}}\right.$ plotted for reference); and (i) Natural gamma radiation (NGR) core log showing the lithological control of density variations with depth; For plotting purposes, all core logs have been filtered with a $0.5 \mathrm{~m}$ boxcar filter. 
The shallow depth interval (Cores C9001C-1H to $9 \mathrm{H}, \sim 0$ - 76 m curated core depth below seafloor) where the formation is mostly unconsolidated is characterized by a continuous and significant amount of VV and DM (average VV + DM 13\%). Down to Core C99901C-34H ( 302 m curated core depth below seafloor) where the hydraulic piston coring system was switched to the extended shoe coring system, core quality is overall good, with reduced core damaged and more localized core voids related to core decompression processes in more consolidated formation (VV + DM usually $<6 \%$ ). Below $~ 333 \mathrm{~m}$ curated core depth below seafloor, overall core quality degrades and VV by itself mostly exceed $20 \%$ (partly filled core liner) due to erosion/surface friction and fracturing (biscuiting) of the core by the rotary coring system. Core C9001C-36X most likely corresponds to an unconsolidated sand layer was not recovered. As the core quality is generally good, the borehole-scale filtered version $(0.5 \mathrm{~m}$ boxcar filter) of the percentiles of the histogram of distribution of the density values match the lithology changes recorded by the MSCL-NGR log.

The different bulk density measurements made at borehole scale in depth (Figure 7) and in cross-plot (Figure 8) views are also compared. The correlation between $\rho_{\mathrm{BULK}}^{\mathrm{MAD}}$ and $\rho_{\mathrm{ND}}^{\mathrm{XRC}}$ (Figure $7(\mathrm{~g})$ and Figure $8(\mathrm{a})$ and Figure $8(\mathrm{~b})$ ) is very good since MAD data have been used to calibrate $\rho_{\mathrm{ND}}^{\mathrm{XRCT}}$. The mismatch between the few ( 3 of 77) erratic MAD data points can be related to 1) manipulation errors in mass and/or weight measurements in MAD experiment, and/or 2) depth mismatch between XRCT images and MAD samples, but are unlikely related to lithology effects that have been not taken into account in the calibration relationship. The correlation between $\rho^{\mathrm{GRA}}$ and $\rho_{\mathrm{ND}}^{\mathrm{XRCT}}$ is also good-at least for the good core quality points (Figure $7(\mathrm{~h})$ and Figure $8(\mathrm{c})$ and Figure $8(\mathrm{~d}))$. As $\rho^{\mathrm{GRA}}$ and $\rho_{\mathrm{ND}}^{\mathrm{XRCT}}$ equally integrate the $\mathrm{VV}, \mathrm{DM}$ and ND fractions of the core, they are of limited geological significance in case of poor core quality. In any case, they provide a lower bound estimate of the core bulk density. In terms of methodology, even if $\rho^{\mathrm{GRA}}$ suffers from localized artificial gaps due to early sampling of cores, the match between $\rho^{\mathrm{GRA}}$ and $\rho_{\text {TOTAL }}^{\mathrm{XRCT}}$ provides an independent validation of the calibration of $\rho_{\mathrm{N}}^{\mathrm{XRCT}}$ data by taking advantage of the more continuous and the higher vertical resolution nature of the $\rho^{\text {GRA }}$ data ( $\sim 6800$ measurements) in respect to the $\rho_{\mathrm{BULK}}^{\mathrm{MAD}}$ data (77 measurements).

In summary, $\rho_{\mathrm{ND}}^{\mathrm{XRCT}}$ provides a $\rho_{\mathrm{BULK}}^{\mathrm{CORE}}$ estimate of quality comparable to $\rho_{\mathrm{BULK}}^{\mathrm{MAD}}$, with a vertical resolution much higher than $\rho^{\mathrm{GRA}}$ which value is highly dependent of core quality and which can possibly suffer from artificial sampling gaps. Note that even if $\rho_{\mathrm{ND}}^{\mathrm{XRCT}}$ is the best proxy for $\rho_{\mathrm{BULK}}^{\mathrm{CORE}}$ in terms of both quality and vertical resolution, it does not reflect the in-situ bulk density of the formation as cores recovered on board experienced 1) decompression because of pressure decrease, 2) porosity rebound and/or 3) variations in sediment rigidity caused by the release of overburden pressure and temperature changes. Even if out of the scope of this paper, procedure to correct the physical property data to in situ values can further be used (e.g. [30]). 

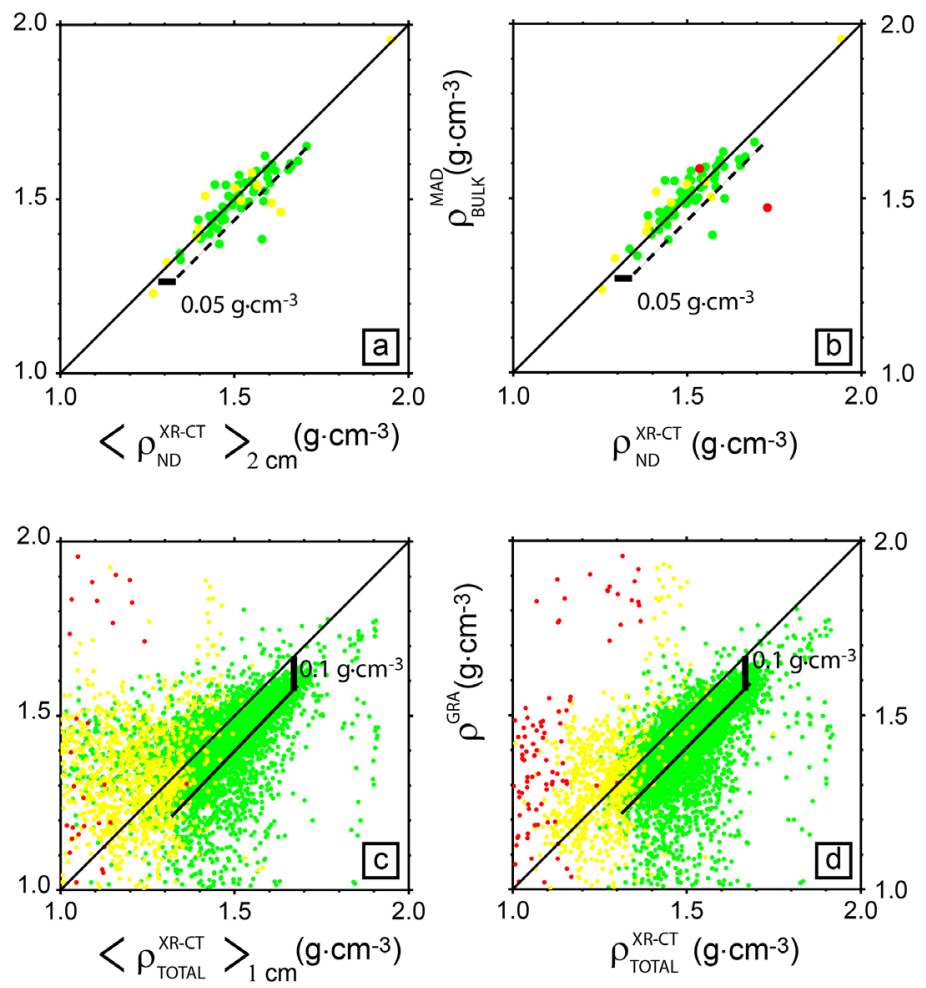

\section{Core Quality Estimate Poor Damaged Good}

Figure 8. Density cross-plots with color coded core quality. (a) $\rho_{\mathrm{BULK}}^{\mathrm{MAD}}$ vs. $2 \mathrm{~cm}$ running average of $\rho_{\mathrm{ND}}^{\mathrm{XRCT}}$ (noted $\left\langle\rho_{\mathrm{ND}}^{\mathrm{XRCT}}\right\rangle_{2 \mathrm{~cm}}$ ) and (b) $\rho_{\mathrm{BULK}}^{\mathrm{MAD}}$ vs. $\rho_{\mathrm{ND}}^{\mathrm{XRCT}} ;(\mathrm{c}) \rho^{\mathrm{GRA}}$ vs. $1 \mathrm{~cm}$ running average of $\rho_{\text {TOTAL }}^{\mathrm{XRCT}}$ (noted $\left.\left\langle\rho_{\mathrm{TOTAL}}^{\mathrm{XRCT}}\right\rangle_{1 \mathrm{~cm}}\right)$ and $(\mathrm{d}) \rho^{\mathrm{GRA}}$ vs. $\rho_{\mathrm{TOTAL}}^{\mathrm{XRCT}}$.

\subsection{X-Ray CT Derived Porosity}

After having validated the sub-mm scale resolution $\rho_{\mathrm{ND}}^{\mathrm{XRCT}}$ as best $\rho_{\mathrm{BULK}}^{\mathrm{CORE}}$ estimate, a sub-mm scale porosity core $\log \left(\phi^{\mathrm{XRCT}}\right)$ is derived by combining $\rho_{\mathrm{ND}}^{\mathrm{XRCT}}$ with the interpolated grain (solid) density core log, $\rho_{\mathrm{SOLID}}^{\mathrm{MADint}}$, according to Equation (3):

$$
\phi^{\mathrm{XRCT}}=\left(\rho_{\mathrm{SOLID}}^{\mathrm{MADint}}-\rho_{\mathrm{ND}}^{\mathrm{XRCT}}\right) /\left(\rho_{\mathrm{SOLID}}^{\mathrm{MADint}}-\rho_{\mathrm{FLUID}}^{\mathrm{CORE}}\right)
$$

where $\rho_{\mathrm{FLUID}}^{\mathrm{CORE}}$ is the averaged density of the fluid (pore) fraction of the core, assumed here to be $1.025 \mathrm{~g} \cdot \mathrm{cm}^{-3}$ (seawater). Computation of $\phi^{\text {XRCT }}$ is technically simplified if 1) $\rho_{\mathrm{SOLID}}^{\mathrm{MADint}}$ has the same sampling as $\rho_{\mathrm{ND}}^{\mathrm{XRCT}}$ (i.e. $0.625 \mathrm{~mm}$ in this work), and 2) if the computations are performed in the scaled curated core depth scale previously described.

$\rho_{\mathrm{BULK}}^{\mathrm{MAD}}$ and $\rho_{\mathrm{ND}}^{\mathrm{XRCT}}$ (filtered with a $0.5 \mathrm{~m}$ and $0.1 \mathrm{~m}$ boxcar filter for plotting purpose) are presented in this new depth scale in Figure $9(\mathrm{a}) . \rho_{\mathrm{SOLID}}^{\mathrm{MAD}}$ and its spline interpolated version, $\rho_{\text {SOLID }}^{\text {MADint }}$, are plotted in Figure $9(\mathrm{~b})$. Assuming the interpolation is valid, the resulting very-high vertical resolution $\phi^{\mathrm{XRCT}}$ is compared with $\phi^{\mathrm{MAD}}$ in Figure 9(c). Except for three main depth intervals (66 - 74, $98-104$ and $172-176 \mathrm{~m}$, scaled curated core depth below seafloor) where MAD 
data are spurious $\left(\rho_{\mathrm{BULK}}^{\mathrm{MAD}}<\rho^{\mathrm{GRA}}\right)$, the match between $\phi^{\mathrm{XRCT}}$ and $\phi^{\mathrm{MAD}}$ is generally within $2 \%$. However, use of discrete MAD data both as input $\left(\rho_{\mathrm{SOLID}}^{\mathrm{MAD}}\right)$ and output $\left(\phi^{\mathrm{MAD}}\right)$ does not provide a validation of the interpolated values. A complete independent validation would have required a separate data set, such as a neutron porosity logs, that were unfortunately not available for this wellbore. In any case, the gain in vertical resolution on one hand, and the simplicity of the procedure on the other hand makes this XR-CT derived porosity estimate valuable for other investigations, in particular to assess magnitude of "porosity rebound" on density estimates [30].

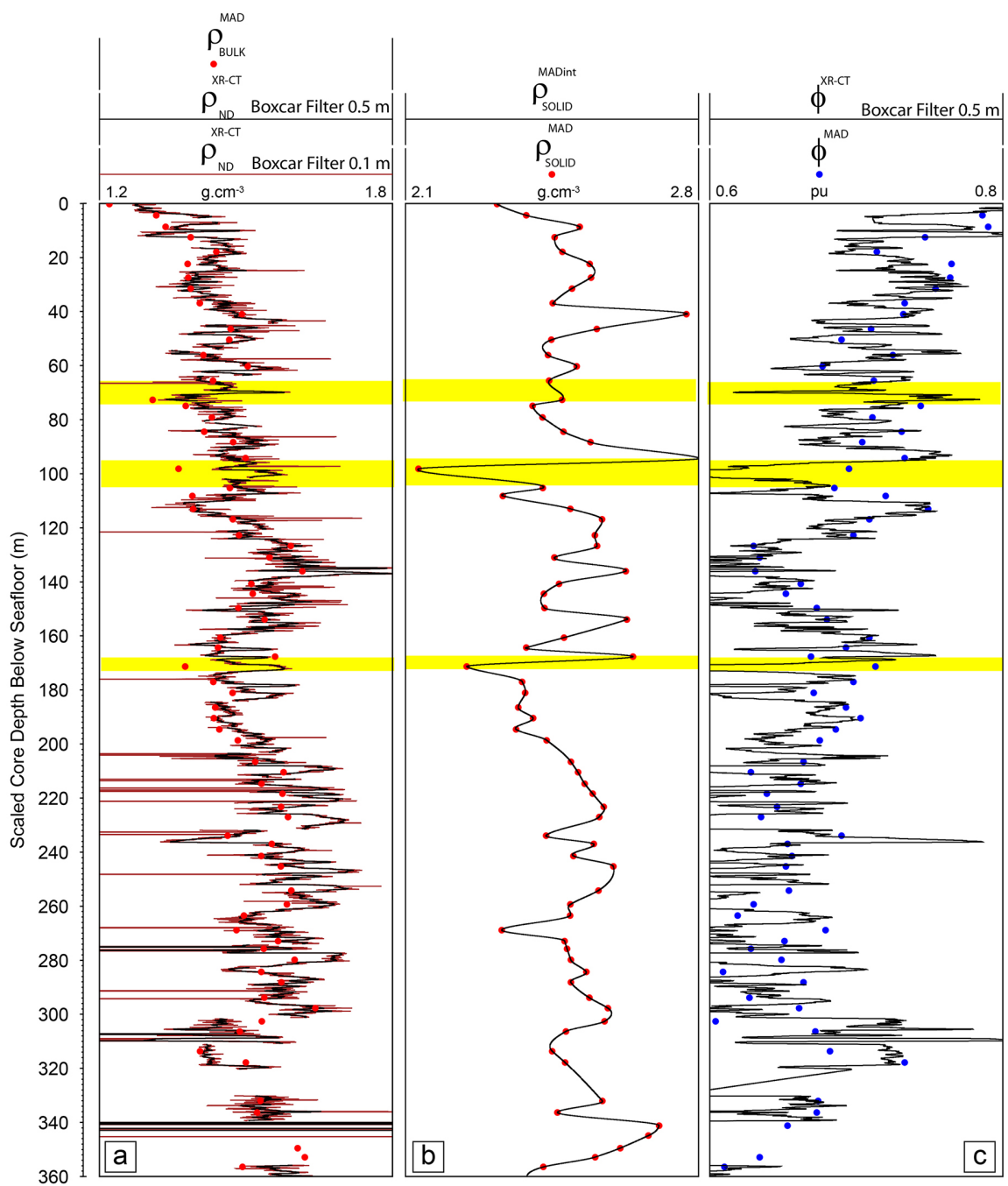

Figure 9. Comparison of porosity estimates at Hole C9001C (scaled core curated depth below seafloor). (a) sub-mm scale vertical resolution XR-CT derived core density ( $\rho_{\mathrm{ND}}^{\mathrm{XRCT}}$ ) (filtered with a $0.5 \mathrm{~m}$ and $0.1 \mathrm{~m}$ boxcar filter for plotting purpose) compared to core bulk density derived from physical property indexes (MAD data, $\rho_{\mathrm{BULK}}^{\mathrm{MAD}}$ ), (b) solid (grain) density derived from MAD data $\left(\rho_{\text {SOLID }}^{\text {MAD }}\right)$ and its spline interpolated version (sub-mm scale resolution, $\left.\rho_{\mathrm{SOLID}}^{\text {MADin }}\right)$, (c) comparison of MAD-derived porosity ( $\phi^{\mathrm{MAD}}$ ) with XR-CT derived porosity $\left(\phi^{\mathrm{XRCT}}\right)$ computed according to Equation (3) by combining $\rho_{\mathrm{ND}}^{\mathrm{xRCT}}$ and $\rho_{\text {SOLID }}^{\text {MADin }}$ and assuming $\rho_{\mathrm{FLUID}}^{\mathrm{CORE}}=1.025 \mathrm{~g} \cdot \mathrm{cm}^{-3}$. 


\subsection{Volume Correction of Core Physical Properties Measurement}

After proper calibration of the MSCL sensors, if the core liner is full, the MSCL measurement, $P_{\mathrm{M}}^{\mathrm{MSCL}}$, reflects the core property, $P^{\mathrm{CORE}}$, in a one-to-one relationship (Figure 10(a)) as Equation (4):

$$
P_{\mathrm{Mfull}}^{\mathrm{MSCL}}=P^{\mathrm{CORE}} \text {. }
$$

This simple relationship breaks down when the core liner is not completely full (Figure 10(b)). In that case, $P_{\mathrm{M}}^{\mathrm{MSCL}}$ include both contributions of the VV $(v)$ and core material fraction (CORE) according to the following general mixture relationship shown as Equation (5):

$$
P_{\mathrm{M}}^{\mathrm{MSCL}}=v P^{v}+(1-v) P^{\mathrm{CORE}}
$$

where $v$ is the integrated volume fraction of VV over the MSCL spatial tool response, and $P^{v}$ is the value of the given property, $\mathrm{P}$, for the VV fraction. This latter Equation (5) is obviously reduced into Equation (4) when $v=0$.

Having in hand 1) the MSCL measurement $\left(P_{\mathrm{M}}^{\mathrm{MSCL}}\right)$ data, 2) the local volume of $v$ automatically derived from XR-CT images, 3) the MSCL sensor's response for the physical property (P), and 4) an a-priori knowledge of the tabulated value for $P^{v}$, volume correction can be applied to derive a volume corrected $P_{\mathrm{Mvc}}^{\mathrm{MSCL}}$, thought to be the best parameter reflecting the true $P^{\mathrm{CORE}}$ value (Figure 10). $P_{\mathrm{Mvc}}^{\mathrm{MSCL}}$ is defined by Equation (6).

$$
\left(P_{\mathrm{M}}^{\mathrm{MSCL}}-P^{v}\right) /(1-v)=P_{\mathrm{Mvc}}^{\mathrm{MSC}} \approx P^{\mathrm{CORE}}
$$

where $v=\int_{z} V V(z) \cdot S(z) \mathrm{d} z$

This procedure was initially applied to NGR and MS routinely measured on recovered cores. For those two physical properties, $P^{v}$ can be taken as zero, independently of the fluid (water/air) filling the VV space. Due to the more complex nature of RES and PWV measurement, the volume correction procedure has not been attempted on those two petrophysical properties. MSCL sensors' response and tabulated value of $P^{v}$ used in this work are given in Table 4.

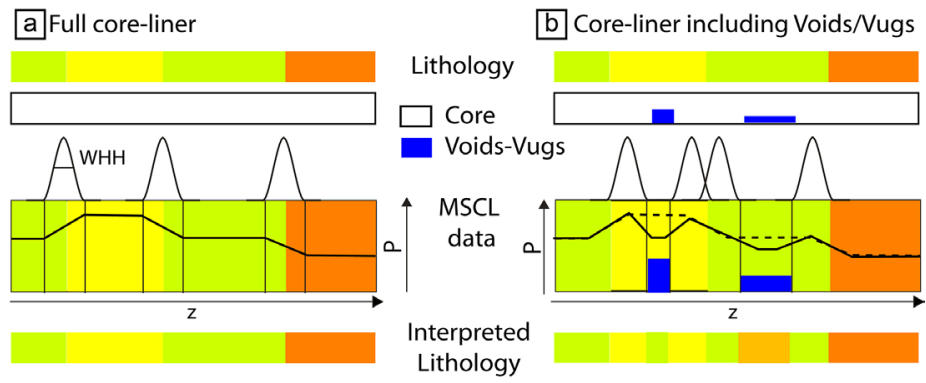

Figure 10. Effect of voids/vugs (VV) on of physical properties (P) measured via Multi-Sensors Core Logger (MSCL). (a) When the core liner is full, the MSCL measurement property $(\mathrm{P})$ data reflect the core physical properties. Taking into account shoulder effects proportional to the spatial resolution of the MSCL sensor's response (width at half height, $\mathrm{WHH}$ ), the variations in $\mathrm{P}$ can be confidently interpreted in term of lithology changes. (b) When the core liner includes local VV, P includes both contributions of the VV and core material. If not recognized and attributed to $\mathrm{VV}$, these local variations can be misinterpreted. 
Table 4. Data used for volume correction of physical properties measured on whole round core via Multi-Sensors Core Logger (MSCL). Spatial resolution (or width at half height, WHH) of the MSCL sensor response and tabulated $P_{\mathrm{AIR}}^{v}$, assuming voids and vugs are filled with air.

\begin{tabular}{ccccc}
\hline Physical Property, P & Unit & Notation & $\begin{array}{c}\text { MSCL } \\
\text { WHH }(\mathrm{cm})\end{array}$ & $P_{\text {AIR }}^{\prime}$ \\
\hline Natural Gamma Radiation & Cps & NGR & 16 & 0 \\
Magnetic Susceptibility & S.I. & MS & 4 & 0 \\
Gamma-ray attenuation density & $\mathrm{g} \cdot \mathrm{cm}^{-3}$ & $\rho^{\text {GRA }}$ & 0.5 & 0 \\
\hline
\end{tabular}

In term of core quality, core C9001C-35X (311.16 - 319.3 curated core depth below seafloor) is characterized by five distinct intervals: 1 ) a good quality interval (311.16 - $311.3 \mathrm{~m}), 2)$ a $\sim 10 \mathrm{~cm}$ interval where automatic core liner mostly failed, 3) a short $(\sim 50 \mathrm{~cm})$ poor core quality interval $(311.4-311.9 \mathrm{~m}), 4)$ a long $(311.9-317.7 \mathrm{~m})$ intermediate core quality section with local peaks in $\mathrm{VV}$, and 5) a $1.2 \mathrm{~m}$ long section of good quality material with the exception of few localized cracks (Figure 11(a) and Figure 11(b)). This later section and short other ones indicated in gray in Figure 11(c) have been sampled just after XR-CT scanning creating gaps in the MSCL data acquisition. As expected volume corrections are small or null in good quality section with NGR and MS approaching $12 \mathrm{cps}$ and $13 \times 10^{-3} \mathrm{SI}$, respectively. Volume corrections in the poor quality section exceed $500 \%$ with corrected values now consistent to good quality portion of the NGR and MS core logs. The intermediate-quality section characterized by $\mathrm{VV} \sim 30 \%$ and $\mathrm{DM} \sim 20 \%$ show correction of about $25 \%-35 \%$ with local increases at local cracks. There is no way to validate those volume corrections except using a semi-qualitatively approach comparing those estimates to adjacent good-quality core sections of similar lithology. Overall, the comparison for NGR and MS shows a fair match. At least this simple use of the VV output provides some awareness on the quality and uncertainty of the physical properties (NGR and MS, Figure 11(d) and Figure 11(e)) core logs in case of partly filled core liner.

As an additional test, the volume correction procedure has been applied to $\rho^{\mathrm{GRA}}$ assuming VV filled with air (Figure 11(f)). Figure 11(f) confirms the good match between the raw $\rho^{\mathrm{GRA}}$ (black) and $\rho_{\mathrm{TOTAL}}^{\mathrm{XRCT}}$ (red, $0.1 \mathrm{~m}$ boxcar filtered) previously discussed. In general volume corrected $\rho^{\text {GRA }}$ (Figure 11(g)) shows a lot of scatter due to the combined effect of the high frequency vertical fluctuation in $\mathrm{VV}$ and the narrow instrument response (spatial resolution $\sim 0.5 \mathrm{~cm}$ ). $\rho_{\mathrm{vc}}^{\mathrm{GRA}}$ (gray) match relatively well with $\rho_{\mathrm{ND}}^{\mathrm{XRCT}}$ (green, $0.1 \mathrm{~m}$ boxcar filtered). However, some local over-corrections, most likely resulting because our main assumption (VV is filled with air) is not always true, still exist. A more detailed procedure taking advantage of the full distribution of the density values below $1.00 \mathrm{~g} \cdot \mathrm{cm}^{-3}$ to fully characterize the density of the fluid(s) filling the VV space would need to be developed. As $\rho_{\mathrm{ND}}^{\mathrm{XRCT}}$ more directly provides the expected 


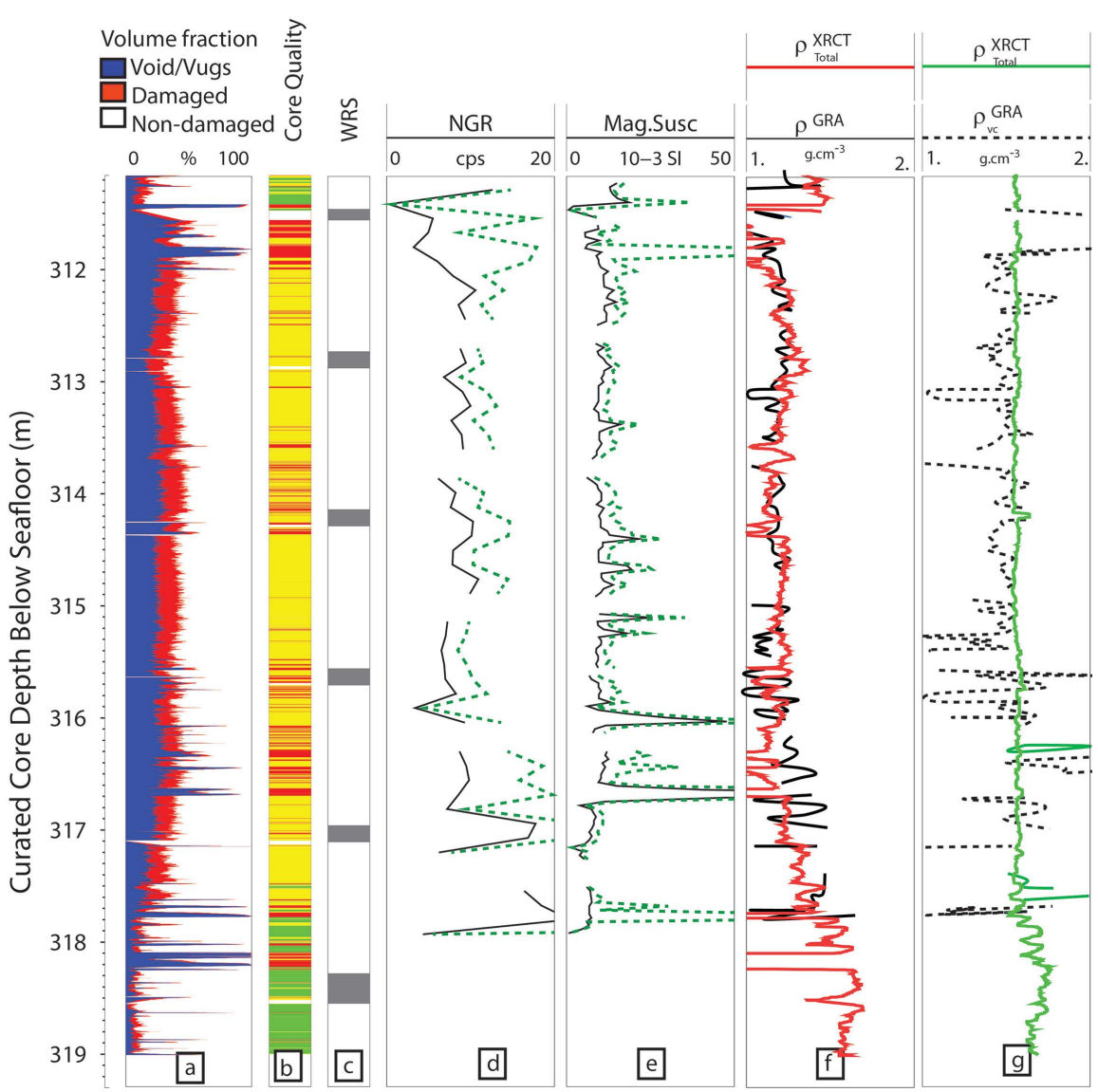

Figure 11. Volume correction of physical properties measured on whole-round sections by Multi-Sensors Core Logger (MSCL) in Hole C9001C (curated core depth below seafloor). (a) Volume contribution of voids/vugs, damaged and non-damaged fraction of the core material, (b) color-coded core quality indicator, (c) location of whole round samples taken before MSCL. Raw (solid) and volume corrected (dash), (d) natural gamma radiation (NGR), (e) magnetic susceptibility (MS), (f) gamma-ray attenuation density $\rho^{\mathrm{GRA}}$ compared to $\rho_{\mathrm{TOTAL}}^{\mathrm{XRCT}}$, and $(\mathrm{g})$ volume corrected GRA density $\left(\rho_{\mathrm{vc}}^{\mathrm{GRA}}\right)$ compared to $\rho_{\mathrm{ND}}^{\mathrm{XRCT}}$.

drilling disturbance free values, $\rho_{\mathrm{BULK}}^{\mathrm{CORE}}$, with a much higher vertical resolution (sub-mm for XR-CT vs. cm scale for MSCL), such development has not been conducted.

\subsection{Seismic Modeling - Well Ties}

Correlations between 1D physical property logs and 2D or 3D seismic reflection data are useful to provide geological information on the nature of seismic reflections and the lateral extent of geological layers [29]. The different resolution of core and seismic data is one major hurdles seismic interpreters face when tying both data sets, core data having a resolution that is at least two orders of magnitude greater [31] [32]. In the absence of sonic log data, [33] used the XR-CT derived density $\log \left(\rho_{\mathrm{ND}}^{\mathrm{XRCT}}\right)$ to compare three different approaches (binomial filtering, seismic wavelet filtering, and Discrete Wavelet Transform filtering (DWT)) to upscale the density log to the seismic scale. For Hole C9001C, best 
ties with the seismic data were obtained when the density log was processed using the DWT, as this method best preserves the physical property changes representing the burial history of geological layers following their deposition. The high-quality and high-resolution nature of the density log on one hand and the multi-scale characteristics embedded in a wavelet transform [34] making it sensitive to both cyclic (e.g. eustatic cycles) and non-cyclic components (e.g. local sediment inputs) of the signal on the other hand, made the seismic modeling successful, even in the absence of sonic log data (Figure 12).

\section{Conclusions}

The presented methodological development for automatic data reduction and quantification of single energy XR-CT scanner images of cores allows 1) identification and quantification of voids/vugs (VV), damaged (DM) and non-damaged (ND) core fractions in terms of volume fraction, average density and mass contribution, 2) estimation of core quality based on abundance of VV and DM fractions, 3) characterization of local variation of core density in terms of radial and angular density distributions, and ultimately 4) derivation of a very-high resolution bulk density core log. Following standard approaches for a quantitative use of XR-CT images for estimating sediment bulk density determination [12] [16], the proposed procedure relies on core-to-core calibration, and also takes into account lithology-controlled mineralogical effects. Additional strength of the developed procedure is that it relies on the full integration of various data sets
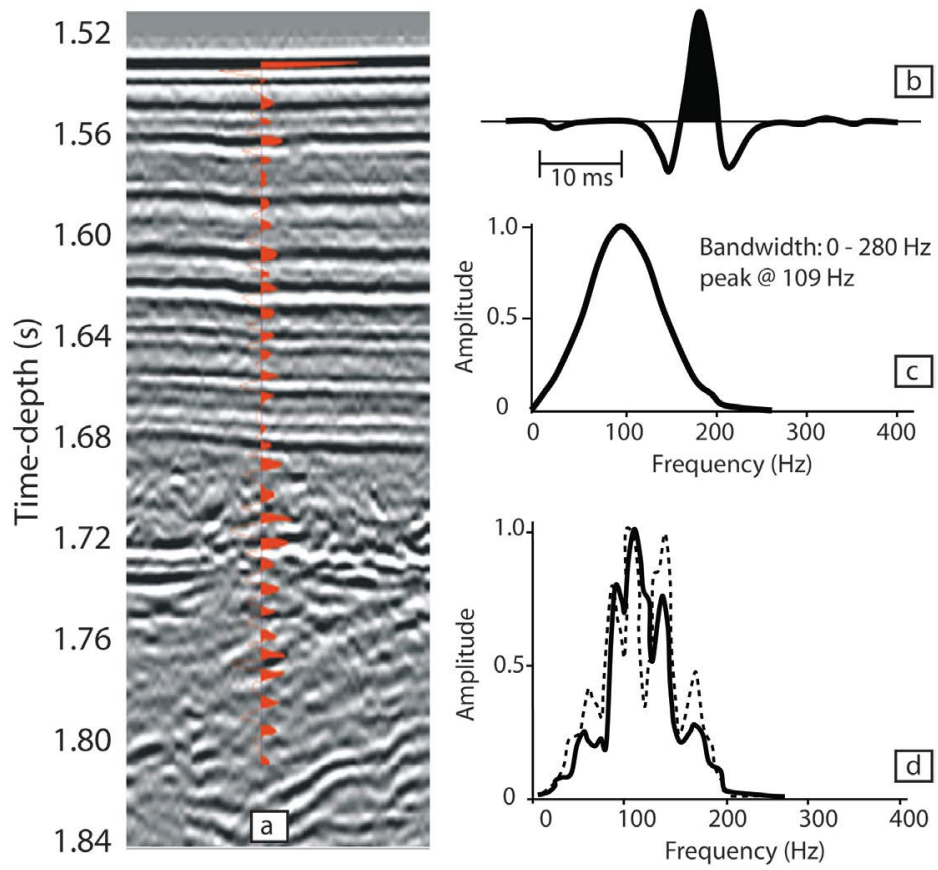

Figure 12. (a) Synthetic seismograms generated using the $\rho_{\mathrm{ND}}^{\mathrm{XRCT}}$ density log upscaled by discrete wavelet filtering. (b) Seismic wavelet used to convolve the reflection coefficient series and (c) its amplitude spectrum. (d) Amplitude spectrum of the synthetic seismograms (solid) compared to the amplitude spectrum of trace 1103 at the borehole location. 
routinely available on IODP expeditions: 1) XR-CT images, 2) VCD and MAD data for lithology-controlled calibration, 3) MSCL $\rho^{\mathrm{GRA}}$ for independent validation of the lithology-based calibration relationships and 4) curatorial and drilling information for the production of the scaled core depth further facilitating the use of the outputs.

In addition to simple $\mathrm{HU}$-conversion, the procedure automatically produces a histogram of distribution of the density values from which the ND fraction of the core can be isolated. As a result, a core bulk density estimate, $\rho_{\mathrm{BULK}}^{\mathrm{CORE}} \sim \rho_{\mathrm{ND}}^{\mathrm{XRCT}}$, free of any drilling disturbance is provided. For slurry cores or cores damaged by the rotary core system, $\rho_{\mathrm{TOTAL}}^{\mathrm{XRCT}}$ and $\rho^{\mathrm{GRA}}$ should be disregarded in terms of absolute density estimates but can still be used for independent validation of the XR-CT derived densities ( $\rho_{\mathrm{TOTAL}}^{\mathrm{XRCT}}$ and $\left.\rho_{\mathrm{ND}}^{\mathrm{XRCT}}\right)$. As illustrated in this paper, the simplest and most direct usage of $\rho_{\mathrm{ND}}^{\mathrm{XRCT}}$ is the derivation of a sub-mm scale resolution porosity, $\phi^{\mathrm{XRCT}}$ provided that $\rho_{\mathrm{SOLID}}^{\mathrm{CORE}}$ and $\rho_{\mathrm{FLUID}}^{\mathrm{CORE}}$ are known. In addition to provide semi-quantitative core quality indicators, quantitative estimates of VV and DM augmented by a knowledge of MSCL sensor responses can be used to apply correction to volume sensitive measurements (NGR, MS and possibly $\rho^{\mathrm{GRA}}$ ) when the core liner is not entirely filled by cored material. Coupled or not with sonic data, the third use of the continuous $\rho_{\mathrm{ND}}^{\mathrm{XRCT}}$ is the generation of seismic impedances/reflection coefficient to generate reflection coefficient series that are later used to build synthetic seismograms to assess seismic-to-well ties and for the seismic upscaling of physical property logs [33]. Finally, the azimuthal distribution of density/HU values can be used to reorient core if orientated borehole wall images are available and if non-ambiguous features can be recognized on both data sets.

In conclusion, the presented procedure and algorithms for automatic data reduction and quantification of single energy XR-CT images of cores are fast and efficient. They reduce data volume by $\sim 90 \%$ and provide valuable outputs in a compact and directly usable form. The procedure provides an integrated framework maximizing the value of drilling/curation, core (VCD, MAD, MSCL), borehole (wireline, logging while drilling scalar and image logs) and seismic data, thus opening avenues for core-log-seismic integration and upscaling of physical properties log. Routine application of this workflow to large scale projects with XR-CT data, in particular IODP expeditions, is recommended.

\section{Acknowledgements}

The authors would like to acknowledge Yoshihisa Kawamura (Manager of IODP Dept of the Center for Deep Earth Exploration, Japanese Implementing organization for the Integrated Ocean Drilling Program, IODP) and Kan Aoike (Staff scientist and Primary Investigator of the 2006 CK06-06 shakedown cruise) for providing access to the data collected during the Chikyu cruise. Calibration of equipment, tests and routine measurements were all conducted by Marine Works Japan Technicians. Hide Sakaguchi, Lalith Wijerathne and Sueki Kentaro 
(IFREE, JAMSTEC) are acknowledged for providing computer resources and technical support in computer settings. Review of the initial manuscript by Quinn Passey (ExxonMobil) improved style and clarity.

\section{Conflicts of Interest}

The authors declare no conflicts of interest regarding the publication of this paper.

\section{References}

[1] Bates, R.H.T., Garden, K.L. and Peters, T.M. (1983) Overview of Computerized Tomography with Emphasis on Future Developments. Proceedings of the IEEE, 71, 533-549. https://doi.org/10.1109/PROC.1983.12594

[2] Kak, A.C. and Slaney, M. (1999) Principles of Computerized Tomography Imaging. IEEE Press, New York.

[3] Hounsfield, G.N. (1972) A Method and Apparatus for the Examination of the Body by Radiation Such as X or Gamma Radiation, Patent Specifications, 1283915. The Patent Office, London.

[4] Duliu, O.G. (1999) Computer Axial Tomography in Geosciences: an Overview. Earth Science Reviews, 48, 265-281. https://doi.org/10.1016/S0012-8252(99)00056-2

[5] Mees, F., Swennen, R.,Van Geet, M. and Jacobs, P. (2003) Applications of X-Ray Computed Tomography in the Geosciences. Geological Society, London, Special Publications, 215, 7-22. https://doi.org/10.1144/GSL.SP.2003.215.01.01

[6] Alshibli, K.A. and Reed, A.H. (2010) Advances in Computed Tomography for Geomaterials. GeoX 2010, ISTE Ltd. and John Wiley \& Sons, Inc., Hoboken.

[7] Holler, P. and Kögler, F.C. (1990) Computer Tomography: A Non-destructive, High Resolution Technique for the Investigation of Sedimentary Structures. Marine Geotechnology, 91, 263-266. https://doi.org/10.1016/0025-3227(90)90041-H

[8] Vinegar, H., De Wall, J. and Wellington, S.L. (1991) CT Studies of Brittle Failure in Castlegate Sandstone. International Journal of Rock Mechanics and Mining Science \& Geomechanics Abstracts, 28, 441-448. https://doi.org/10.1016/0148-9062(91)90082-W

[9] Swennen, R., Poot, B. and Marchal, G. (1991) Computerized Tomography as a Tool in Reservoir Characterization. Zentralblatt für Geologie und Paläontologie, Teil I, 8, 1105-1124.

[10] Schaoping, F., Werner, F. and Brossman, J. (1994) Computed Tomography Application in Studding Biogenetic Structures in Sedimentary Cores. Palaeos, 9, 116-119. https://doi.org/10.2307/3515084

[11] Bonner, B.P., Roberts, J.J., Schneberk, D.J., Marsh, A., Ruddle, C. and Updike, E. (1995) X-Ray Tomography of Preserved Samples from the Geysers Scientific Core Hole. Department of Energy, DOE Report UCRL-JC-119573.

[12] Boespflug, X., Long, B.F.N. and Ochietti, S. (1995) CAT-Scan in Marine Stratigraphy: A Quantitative Approach. Marine Geology, 122, 281-301. https://doi.org/10.1016/0025-3227(94)00129-9

[13] Coshell, L., McIver, R.G. and Chang, R. (1994) X-Ray Computed Tomography of Australian oil Shales: Non-Destructive Visualization and Density Determination. Fuel, 73, 1317-1321. https://doi.org/10.1016/0016-2361(94)90307-7

[14] Duliu, O.G., Tufan, M. and Szobotka, S. (1997) Computer Axial Tomography In- 
vestigation of Polymetallic Nodules. Marine Geology, 138, 303-311. https://doi.org/10.1016/S0025-3227(97)00011-X

[15] Long, B.F.N. and Ross, N. (1991) Etudes Océanographiques Physiques et Biologiques: Analyses Complémentaires, Rapp. INRS-Oceanol., Proj. SEBJ 1LP-892-1-02.

[16] Orsi, T.H., Edwards, C.M. and Anderson, A.L. (1994) X-Ray Computed Tomography: A Nondestructive Method for Quantitative Analysis of Sediment Cores. Journal of Sedimentary Research $A, 64,690-693$. https://doi.org/10.1306/D4267E74-2B26-11D7-8648000102C1865D

[17] Amos, C.L., Sutherland, T.F., Radzijewski, B. and Doucette, M. (1996) A Rapid Technique to Determine Bulk Density of Fine-Grained Sediments by X-Ray Computed Tomography. Journal of Sedimentary Research, 66, 1023-1025. https://doi.org/10.1306/D4268144-2B26-11D7-8648000102C1865D

[18] Tsuchiyama, A., Hanamoto, T., Nakashima, Y. and Nakano, T. (2000) Quantitative Evaluation of Attenuation Contrast of Minerals by Using a Medical X-Ray CT Scanner. Journal of Mineralogical and Petrological Sciences, 95, 125-137. https://doi.org/10.2465/jmps.95.125

[19] Duchesne, M.J., Moore, F., Long, B.F.N. and Labrie, J. (2009) A Rapid Method for Converting Medical Computed Tomography Scanner Topogram Attenuation Scale to Hounsfield Unit Scale and to Obtain Relative Density Values. Engineering Geology, 103, 100-105. https://doi.org/10.1016/j.enggeo.2008.06.009

[20] Aoike, K. (2007) CK06-06 D/V Chikyu Shakedown Cruise Offshore Shimokita. Laboratory Operation Report, Science and Planning Department, Center for Deep Earth Exploration, 73 p.

[21] GE Healthcare (2006) Light Speed Series Learning and Reference Guide. 936 p.

[22] ASTM (1990) Standard Method for Laboratory Determination of Water (Moisture) Content of Soil and Rock. Annual Book of ASTM Standards, D 2216-90 (Revision of 2216-63, 2216-80).

[23] Tittman, J. and Wahl, J.S. (1965) The Physical Foundations of Formation Density Logging (Gamma-Gamma). Geophysics, 30, 284-294. https://doi.org/10.1190/1.1439574

[24] Hammersberg, P. and Mangard, M. (1998) Correction of Beam Hardening Artefacts in Computerized Tomography. Journal of X-Ray Science and Technology, 8, 75-93.

[25] De Man, B., Nuyts, J., Dupont, P., Marchal, G. and Suetens, P. (2001) An Iterative Maximum-Likelihood Polychromatic Algorithm for CT. IEEE Transactions on Medical Imaging, 20, 999-1008. https://doi.org/10.1109/42.959297

[26] Ketcham, R.A. and Carlson, W.D. (2001) Acquisition, Optimization and Interpretation of X-Ray Computed Tomographic Imagery: Applications to the Geoscience. Computers and Geosciences, 27, 381-400. https://doi.org/10.1016/S0098-3004(00)00116-3

[27] Gaillot, P., Punongbayan, J.T. and Rea, B. (2004) Map-Plot and Bgg-Plot: Software for Integration of Geoscience Datasets. Computers and Geosciences, 30, 73-89. https://doi.org/10.1016/j.cageo.2003.10.003

[28] Wessel, P. and Smith, W.H.F. (1995) New Version of the Generic Mapping Tools Released. EOS Transactions American Geophysical Union, 76, 329. https://doi.org/10.1029/95EO00198

[29] Gaillot, P., Masago, H., Kyaw Thu, M. and Ito, H. (2006) Core-Log-Seismic Integration-New Scientific and Technological Challenges. Scientific Drilling, 2, 52-53. https://doi.org/10.5194/sd-2-52-2006 
[30] Rea, B.R. and Gaillot, P. (2004) Correction of the Core Mcd-Depth and Physical Property Data, to In-Situ Values Using Core-Log Depth Miss-Match Rebound Coefficients. Proceedings of the Ocean Drilling Program, Scientific Results, Volume 199.

http://www-odp.tamu.edu/publications/199_SR/VOLUME/CHAPTERS/208.PDF

[31] Dubrule, O. (2003) Geostatistics for Seismic Data Integration in Earth Models. Society of Exploration Geophysicists/European Association of Geoscientis and Engineers. https://doi.org/10.1190/1.9781560801962

[32] Braaskama, H., Drijkoningen, G.G., Filippidou, N., Kenter, J.A.M. and Proust, J.N. (2006) The Origin and Nature of Seismic Reflections of Sharp-Based Shoreface Deposits (Upper Jurassic Siliclastics, Northern France). Geophysical Prospecting, 54, 211-236. https://doi.org/10.1111/j.1365-2478.2006.00529.x

[33] Duchesne, M.J. and Gaillot, P. (2011) Did You Smooth Your Well Logs the Right Way for Seismic Interpretation? Journal of Geophysics and Engineering, 8, 514-523. https://doi.org/10.1088/1742-2132/8/4/004

[34] Daubechies, I. (1992) Ten Lectures on Wavelets. CBMS-NSF Regional Conf. Ser. in Appl. Math., Vol. 61, Society for Industrial and Applied Mathematics, Philadelphia. 